\title{
Method to Increase the Surface Area of Titania Films and Its Effects on the Performance of Dye-Sensitized Solar Cells
}

\author{
Young-Seon Ko, ${ }^{\dagger}$ Min-Hye Kim, ${ }^{\ddagger}$ and Young-Uk Kwon ${ }^{\ddagger \neq, *}$ \\ ${ }^{\dagger}$ SKKU Adranced Institute of Nanotechnologv, Sunghunkw an Lnwersity, Suwon 4+0-746, Korea \\ ${ }^{*}$ E-mail: wrkwonciskkuedu \\ -Department of Chemistry, BK-2I School of Chemical haterials Science, Sungknukwan Lhwersitv, Sum $+40-746$, Korea \\ Received November 27, 2007
}

\begin{abstract}
We report a method to increase the surface area of the titania films used as the anodes of dye-sensitized solar cells (DSSCs) by applying additional titania-coating. The modification was achieved by spin-coating a coating solution that contained a surfactant with a titania source onto the titania electrodes. followed by calcination. Previous similar attempts without a surfactant all reported decreased surface areas. We fabricated DSSCs by using the modified titania films as the anode and measured their performances. The increased surface area increased the amount of adsorbed dy'es. which resulted in increased current densities. At the same time. the titania-coating increased both the open-circuit voltage and the current density by reducing the chargerecombination rates of the injected electrons. similar to the results of literatures. Therefore, our method shows an additional mechanism to increase the current density of DSSCS in addition to the other mechanisms of surface modifications with titania-coatings.
\end{abstract}

Key Words : Dye-sensitized solar cell, Titania-coating, Surface modification

\section{Introduction}

Dye-sensitized solar cells (DSSCs) have received a great deal of attention as an economical alternative to the conventional silicon-based solar cells. ${ }^{1.2}$ There have been many attempts to improve the performance of DSSCs. Among the various approaches. many groups reported that the performance of DSSCs could be improved by surface treatments of the titania electrode. ${ }^{3-10}$ Most of them show that coating the titania surface with wide band gap materials such as $\mathrm{ZrO} \mathrm{O}_{3} . \mathrm{In}_{-} \mathrm{O}_{3}, \mathrm{Al}_{2} \mathrm{O}_{3}$. or $\mathrm{Nb}_{2} \mathrm{O}_{3}$ increases both short-circuit current $\left(\mathrm{J}_{\mathrm{sc}}\right)$ and open-circuit voltage $\left(\mathrm{V}_{\mathrm{oc}}\right)$ by reducing the charge-recombination rate ${ }^{6-10}$ There are also some reports on treating the titania electrode with titanium species to form titania-coatings that also show some positive effects. ${ }^{8.11-14}$ In this case. the improved efficiencies were explained as the increased conductivity of the titania electrode by forming titania necks between the titania particles and the increased amount of adsorbed dyes. However. interestingly: in all cases of titania-coatings. the specific surface area of the electrode was reported to decrease: the increase of the amount of adsorbed dyes was attributed to the increase of the amount of titania or the increase of binding sites.

We note that all of the experiments on titania-coating treatments have been performed by either dipping the electrode into an aqueous solution of $\mathrm{TiCl}_{4}$ or spin-coating such a solution on the electrode. We conjectured that the use of an aqueous solution might result in rather large titania particles in the solution. which might deviate from the idea of thin layer coating on the surface of titania electrodes. Indeed a few papers reported that the amount of titania was increased by $28 \%$ after dipping the electrode into an aqueous $\mathrm{TiCl}_{4}$ solution. thereby decreasing the surface area. ${ }^{12.13}$
Therefore. it seems that the performance of DSSCs can be further improved if a method to increase the surface area is found.

In the present paper. we applied a surface-modification method that could increase the surface area of the titania electrode. In this method. we employed a spin-coating technique using an ethanol solution of $\mathrm{TiCl}_{+}$mixed with a surfactant. $\mathrm{F} 127\left(\mathrm{EO}_{117} \mathrm{PO}_{7 \mathrm{i}} \mathrm{EO}_{11 \mathrm{j} 7}\right.$ : $\mathrm{EO}=$ ethylene oxide. $\mathrm{PO}$ $=$ propylene oxide). This teclunique is similar to that for forming mesoporous titania thin films with well ordered pores. ${ }^{1516}$ The details of the surface modification and the performance of DSSCs are reported herein.

\section{Experimental Methods}

Titania films with thickness of $12 \mu \mathrm{m}$ were prepared on fluorine-doped tin oxide $\left(\mathrm{SnO}_{2} \mathrm{~F}\right)$ covered glass substrates (TEC glass. Pilkington) by doctor-blading method with a titania slurry. The slurry of titania was prepared by grinding titania nanoparticles (Degussa P25) with acetylacetone. hydroxylpropyl cellulose and distilled water. The film thickness was controlled by $3 \mathrm{M}$ adhesive tapes. These films were then sintered at $450^{\circ} \mathrm{C}$ for $30 \mathrm{~min}$ in air.

The solution for titania-coating was prepared by dissolving $1.9 \mathrm{~g}$ of anhydrous $\mathrm{TiCl}_{4}$ and $0.5 \mathrm{~g}$ of $\mathrm{F} 127 \mathrm{in} 10 \mathrm{~g}$ of anhydrous ethanol. and was spin-coated on the titania electrode films under controlled humidity of $70-72 \%$ and temperature of $27-30^{\circ} \mathrm{C}$. Measured amounts of the solution were spin-coated on the titania electrodes with a fixed area $\left(1.5 \times 1.5 \mathrm{~cm}^{2}\right)$. The resultant films were then dried and aged at $18-20^{\circ} \mathrm{C}$ under a relative humidity of $75-80 \%$ for 2 days. followed by heating at $300{ }^{\circ} \mathrm{C}$ for $2 \mathrm{~h}$ to remove the surfactant. The untreated film with the coating solution was 
also heated under same condition for comparison. After calcination. a part of each film was scraped off to make a rectangular shape of ca. $0.7 \times 0.8 \mathrm{~cm}^{2}$ in area. These films were then inmersed in a $0.3 \mathrm{mM}$ ethanol solution of cisbis(isothiocyanato)bis(2.2'-bipy ridyl-4, 4'-dicarboxylato)ruthenium(II) (N3, Solaronix S. A.) for $22-24 \mathrm{~h}$. The counter electrodes were prepared by dropping a $10 \mathrm{mM}$ of chloroplatinic acid solution on TEC glasses, followed by heating at $450^{\circ} \mathrm{C}$ for $30 \mathrm{~min}$ in air.

The DSSCs were fabricated with the counter electrode. the dye-adsorbed titania electrode, and a redox electroly te. The redox electrolyte used in our experiment was composed of $0.1 \mathrm{M}$ lithium iodide. $0.05 \mathrm{M}$ iodine. $0.6 \mathrm{M}$ l-propyl-2,3dimethylinidazolium iodide (DMPII). and $0.5 \mathrm{M}$ tert-butyl pyridine in propionitrile. We also prepared DSSCs composed of titania electrodes without the titania-coating for a reference. The current-voltage characteristics of the DSSCs were measured with a Keithley 2400 source-meter in the dark and under illumination of a $300 \mathrm{~W}$ Xenon lanip.

The Brunauer-Enmett-Teller (BET) specific surface areas $\left(S_{\text {比 }}\right)$ of the titania electrodes were calculated by analyzing the $\mathrm{N}_{2}$ adsorption-desorption isotherms at $77 \mathrm{~K}$ (Sorptomatic 1990). For these measurements. the titania films were scraped off from the substrates. The morphology of the titania electrode was observed with a field emission scanning electron microscopy (FE-SEM; JEOL JSM-7401F). The anount of dyes adsorbed on each electrode was determined by extracting then into water and recording the UV-vis absorption spectrun (Scinco S-3100 spectrophotometer) of the solution

\section{Results and Discussion}

In this study, we prepared titania-coated titania films and used them to assenible DSSCs. The coating solution was prepared by dissolving $\mathrm{TiCl}_{4}$ and $\mathrm{F} 127$ in ethanol. This formulation was used to form mesoporous titania thin films with about $7 \mathrm{~mm}$ pores. through the self-assembly of the titania species and F127..$^{15.15}$ It was our intention that the inclusion of F127 in the coating could result in titaniacoatings with high surface areas. Table 1 lists the specific surface areas of the titania films. calculated from the $\mathrm{N}_{2}$ adsorption-desorption isotherms. The films are denoted with the anount of the coating solution used to modify the surface. Therefore. S5. \$20, and S35. respectively indicate the titania films that are prepared with 5,20 , and $35 \mu \mathrm{L}$ of the coating solution. The DSSCs prepared with these electrodes are also denoted by these names. The untreated film and the DSSC with such an electrode are denoted as SO. Because we used spin-coating technique that may cause

Table 1. Conditions of surface modification and resultant specific surface areas of titania films

\begin{tabular}{lcccc}
\hline & $S 0$ & $S 5$ & $S 20$ & $S 35$ \\
\hline Amount of the coating solution used $(, L))$ & 0 & 5 & 20 & 35 \\
$S_{\text {BET }}\left(\mathrm{m}^{2} / \mathrm{g}\right)$ & 53.0 & 59.4 & 58.0 & 58.2 \\
\hline
\end{tabular}

some loss of the solution, these numbers may be regarded as the upper limits for the amounts of titania added as coatings. Assuming that the density of the titania-coating and that of the titania electrode film are the same. the maximum obtainable weight gains are calculated to be 4,17 . and $29 \%$. for S5, S20. and $\$ 35$. respectively.

As intended, the titania-coatings with various anounts of the coating solutions increased the specific surface areas. However. the increment of the surface area is not well correlated with the anount of titania-coating solution. The specific surface area shows a large increase upon applying a small amount of coating solution (from $\mathrm{S} 0$ to $\mathrm{S} 5$ ). However, further increase of the amount of titania-coating (to $\$ 20$ and S35) reduces the surface area from that of $\$ 5$. although they still showed increased surface areas from that of untreated film ( $\mathrm{SO}$ ). The fact that all of the surface-treated films showed increased surface areas from that of untreated films is quite contrary to the literature, which reported reduction of surface areas by as large as $8 \% .^{811,12}$ Apparently. the use of the surfactant in the present study is the key factor for the different results.

The UV-vis absorption spectra of the solutions of the dyes extracted from the dye-adsorbed titania films (Figure 1) show the same trend as the specific surface areas by the $\mathrm{N}_{2}$ adsorption-desorption measurements mentioned above. That is, the amount of adsorbed dyes first increases on moving from $\mathrm{S} 0$ to $\mathrm{S} 5$ and then slightly decreases on further moving to $\$ 20$ and $\$ 35$. $\$ 20$ and $\$ 35$ films show almost the same values for both the specific surface area and the amount of adsorbed dyes.

In an effort to understand the nature of changes brought in by the titania-coating. we studied the films by FE-SEM. The cross-section FE-SEM images do not reveal any difference among the films. probably, because the amount of titania added is very small. On the other hand, the plain-view images give some insight. Figure 2 shows the plane-view FE-SEM inages of the titania electrodes before and after the modification. These images are similar to each other.

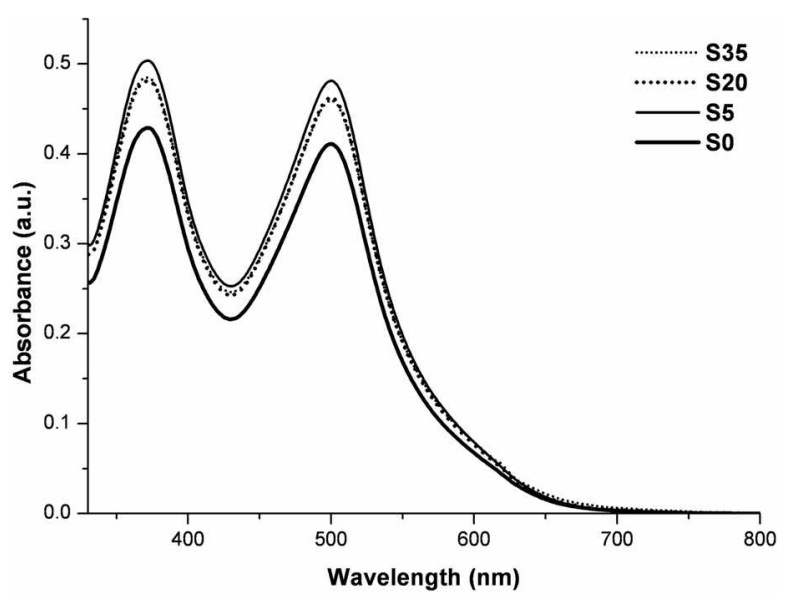

Figure 1. UV-vis absorption spectra of $\mathrm{N} 3$ dye extracted solutions from the dye-adsorbed titania films with and without the titaniacoating. 
(a)

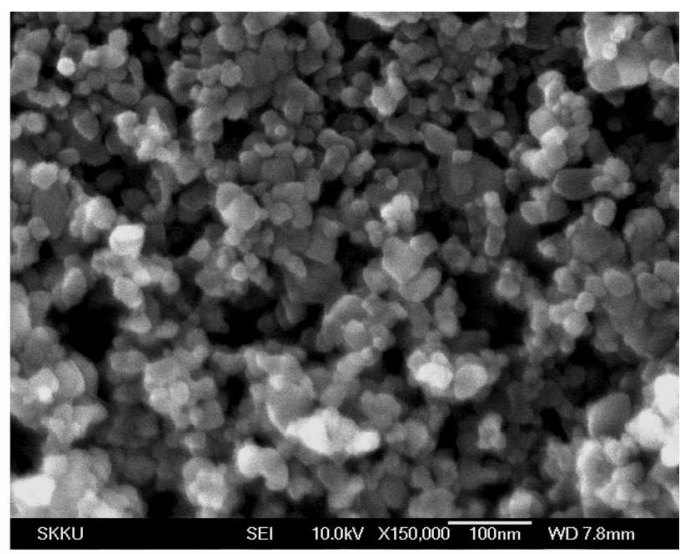

(b)

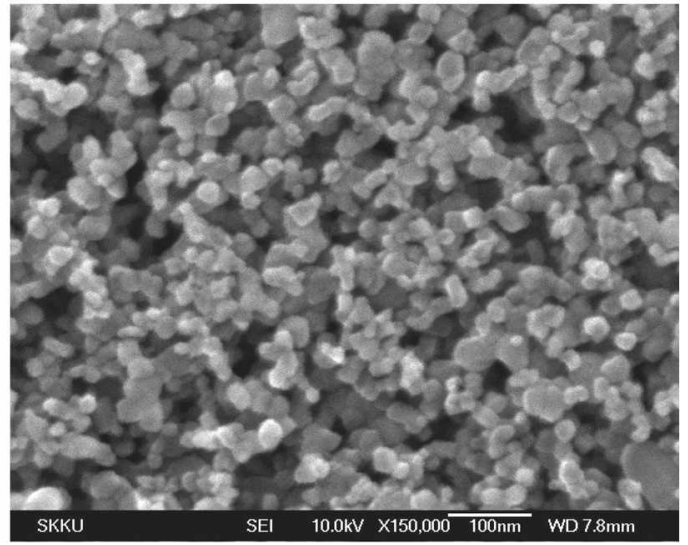

Figure 2. FE-SEM mages of titania films: (a) untreated titania film (SO); (b) titania-coated titania film (S20)

However, close inspection reveals that the particle size of $\mathrm{S} 20$ is smaller than that of $\mathrm{S} 0$. These images may be interpreted as that the titania-coating with surfactant molecules forms an overlayer with finer particles, which explains the increased specific surface area upon titania-coating. However. one cannot rule out the possibility that a part of the coating solution smeared into the titania film. which may be the explanation for the reduction of the specific surface area on moving from $\$ 5$ to both $\mathrm{S} 20$ and $\$ 35$. The smearing of the coating solution into the film may increase the interparticle connections. which results in a lower electric resistance for electron-migration through the titania film to the TEC glass. ${ }^{8.11 .17}$

The photovoltaic data for our DSSCs are listed in Table 2. For each type of DSSCs, we prepared six to eight cells. The values in Table 2 are their averaged values. As can be seen from the small standard deviations of the measurements. these cells and their performance data are reproducible

The trends of the DSSC performance with the amount of titania-coating can be summarized as follows: (1) Both short-circuit current $\left(J_{\mathrm{sc}}\right)$ and open-circuit voltage $\left(V_{o c}\right)$ increase on increasing the amount of titania-coating until S20. On further increase of the titania-coating to S35. $J_{\mathrm{sc}}$ does not change from that of $\mathrm{S} 20$, but $V_{o u}$ is slightly decreased. (2) $J_{\mathrm{sc}}$ and $V_{o c}$ show different rates of increase on moving from $\mathrm{SO}$ to $\mathrm{S} 20 . J_{\mathrm{sc}}$ shows an abrupt increase by the first $5 \mu \mathrm{L}$ of the coating solution and then the rate is reduced.
Table 2. Photovoltaic data for DSSC comprising titania electrodes with various amounts of titania-coatings

\begin{tabular}{lcccc}
\hline Sample $^{*}$ & $J_{\text {sc }}\left(\mathrm{mA} / \mathrm{cm}^{2}\right)$ & $I_{\Delta c}(\mathrm{~V})$ & $\mathrm{FF}(\%)$ & $\eta(\%)$ \\
\hline $\mathrm{S} 0(7)$ & $12.3 \pm 0.7$ & $0.713 \pm 0.014$ & $0.545 \pm 0.02$ & $4.76 \pm 0.17$ \\
$\mathrm{~S} 5(8)$ & $13.2 \pm 0.5$ & $0.716 \pm 0.016$ & $0.544 \pm 0.01$ & $5.13 \pm 0.25$ \\
$\mathrm{~S} 20(8)$ & $13.3 \pm 0.7$ & $0.726 \pm 0.012$ & $0.548 \pm 0.01$ & $5.29 \pm 0.27$ \\
$\mathrm{~S} 35(6)$ & $13.3 \pm 0.8$ & $0.724 \pm 0.012$ & $0.550 \pm 0.02$ & $5.31 \pm 0.30$ \\
\hline
\end{tabular}

The numbers in the parentheses are the number of cells tested.

whereas the increase of $V_{<k}$ is almost proportional to the amount of the coating solution used.

There are several different factors that can influence the DSSC performance. The influence of the titania-coatings with varied amounts can also be analyzed in terms of many different factors. One of the obvious factors is the variation of the surface area (and. consequently. the amount of adsorbed dyes) with the amount of titania-coating. Therefore, the abrupt increase of $J_{\mathrm{sc}}$ on moving from $\mathrm{S} 0$ to $\mathrm{S} 5$ appears to be mainly because of the increased amount of adsorbed dye due to the increase of the surface area. However, there must be other factors involved because $V_{o c}$ is also increased slightly.

Although the surface area is decreased on moving from $\mathrm{S} 5$ to $\mathrm{S} 20$. the fact that both $J_{s c}$ and $V_{c c}$ are increased requires an explanation different from that between $\mathrm{S} 0$ and $\mathrm{S} 5$. The amount of adsorbed dye is also decreased, which is not correlated with the increase of $J_{\mathrm{sc}}$. To explain these phenomena, we measured the dark currents of the DSSCs Although the dark-current measurement does not yield the charge-recombination rates directly. it can tell which cell has the lower (or higher) charge-recombination rate. ${ }^{18}$ Figure 3 shows the dark current-voltage characteristics of the DSSCs in this study. The dark currents of DSSCs with thicker coatings ( $\mathrm{S} 20$ and $\mathrm{S} 35$ ) are lower than those of thimner or no coating ( $\mathrm{S} 0$ and $\mathrm{S} 5$ ). clearly showing that the chargerecombination rates of the former group are smaller than those of the latter one.

$V_{v c}$ and $J_{\mathrm{sc}}$ of a DSSC are related by the following equation $(1):^{14}$

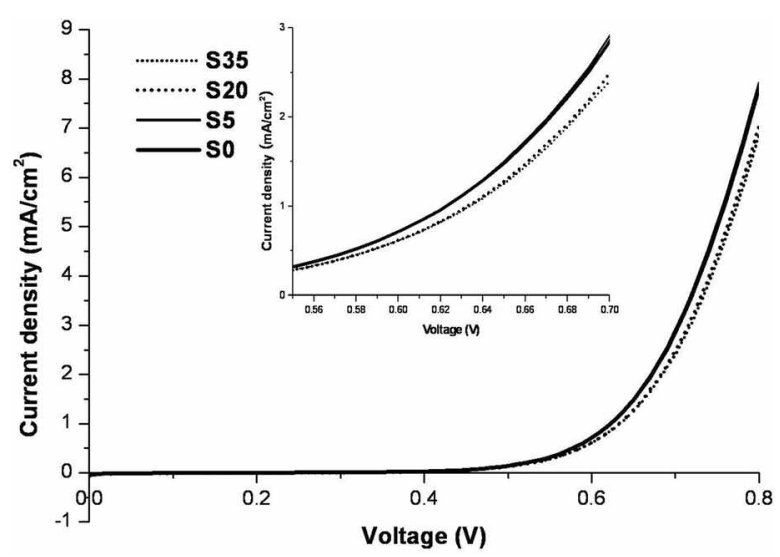

Figure 3. Dark current-voltage characteristics of DSSCs before and after titania-coating. "I he inset shows the part magnified from 0.55 to $0.70 \mathrm{~V}$. 


$$
V_{o c}=\left(\frac{k_{B} T}{q}\right) \ln \left(\frac{I_{i n j}}{n_{c b} k_{e t}\left[I_{3}^{-}\right]}\right)
$$

where $k_{B} . T, q, n_{c b}$ and $k_{e t}$ are the Boltzmann constant the absolute temperature. the electron charge. the concentration of electrons at the electrode surface. and the rate constant for the reduction of the triiodide $\left(I_{3}^{-}\right)$in the electrolyte by electrons in the conduction band of the titania electrode. respectively. $I_{\text {intj }}$ is the current due to the electrons from the excited dyes. $n_{i b} k_{i t}\left[I_{3}^{-}\right]$can be identified with the chargerecombination current. $I_{r}$. Therefore equation (1) can be rewritten as:

$$
V_{o c}=\left(\frac{k_{B} T}{q}\right) \ln \left(\frac{I_{m i n}}{I_{r}}\right)
$$

Because $I_{\text {iftj }}$ is proportional to the amount of dyes on the electrode. it must decrease on moving from S5 to both S20 and $\mathrm{S} 35$. As noted above from the dark current data. $I$. also decreases in the similar manner. By equation (la). the fact that $V_{o c}$ increases suggests that the decreasing rate of $I_{r}$ is faster than that of $I_{\text {intj }}$ on increasing the amount of titaniacoating. $J_{\mathrm{sc}}$ is directly related with the net current between $I_{i n j}$ and $I_{r}$ as in the equation (2) ${ }^{1.9}$

$$
I=I_{i, j j}+I_{r}
$$

As a result. $J_{\mathrm{sc}}$ is also increased with the increase of the amount of titania-coating even though the amount of adsorbed dyes may decrease. explaining the increases of both $J_{\mathrm{sc}}$ and $V_{o c}$ on moving from S5 to both $\mathrm{S} 20$ and S35. In addition. the increase of $V_{\infty}$ means that the charge-recombination rate is decreased by lower electric resistance for electron-migration. As mentioned above. this decrease is attributed to the connections among titania nanoparticles. Therefore. the interparticle connections would be enhanced above a critical amount of the coating solution.

Assuming that all of the titania species spin-coated were transformed into the titania-coatings without loss of materials during the spin-coating. the titania film in S35 would have gained $29 \%$ of mass, close to the anounts of mass gains of $28 \%$ reported in some of the literature on coating with titania. It also appears that the operating mechanisnis to increase $J_{s c}$ and $V_{o c}$ in our study and in the literature are the same despite the different trends of the surface areas upon titania-coating in these cases. In fact. although the increase of $J_{\mathrm{sc}}$ on moving from $\mathrm{S} 0$ to $\mathrm{S} 5$ is mainly due to the increase of the amount of dyes adsorbed the $V_{o c}$ also shows a tendency to increase. which can be explained with the above discussed mechanism. Therefore, the performance of our DSSCs is affected by the factor of enhanced interparticle connections rather than that of increased surface area as the anlount of the coating solution is getting larger.

\section{Conclusions}

We report on the influence of different amount of the coating solution, which is composed of $\mathrm{TiCl}_{4} . \mathrm{F} 127$, and ethanol, on the performance of DSSCs. For the titania film treated with a small amount of the coating solution ( $\mathrm{S} 5$ ). $J_{\mathrm{sc}}$ was improved by the increase of both the surface area and the amount of adsorbed dyes. When the amount of the solution deposited on titania film is more than a critical value ( $\$ 20$ and $\$ 35$ ). comections among titania nanoparticles were enlanced. which resulted in the increased conductivity of the titania electrode. For S20 and S35. therefore, the increase of $J_{s c}$ was attributed to the factor of enlanced interparticle connections rather than that of increased surface area. which is compatible with the fact that $V_{o c}$ was increased. In conclusion. we found that the increase of the surface area may contribute to the improvement of the cell performance. However. it appears to be limited only when the amount of titania-coating is very small. which is not sufficient to achieve the optimum performance by itself.

Acknowledgments. This work was supported by the Korea Research Foundation Grant funded by the Korean Government (MOEHRD) (KRF-2005-005-J11903). We also thank CNNC and KOSEF (05M0300-29110) for the funancial supports.

\section{References}

1. O'Regan1. B.: Grätzel. M. Nantme 1991. 353.737

2. Grătzel, M. Nattre 2001, $1+1,338$

3. Hao. S.; Wu. J.: Fan, L.; Huang, Y.: Lin, J.; Wei. Y. Solar Energ, 2004. 76,745

4. Wang. Z.-S.: Yamaguchi. I.: Sugihara. H.: Arakawa. H. Langmin 2005. 21. 4272

5. Diamant. Y.: Chen1. S. G.: Melamed. O.: Zaban. A. J. Phws Chent. B 2003, 107. 1977.

6. Menzies. D.; Dai. Q.: Cheng, Y.B.: Simon. G.; Spiccia, L. Mater: Lett. 2005, 59. 1893.

7. Palomares. E.: Clifford. J. N.: Haque. S. A.: Lutz. T.: Durrant. J. R. J.Am. Chem. Soc. 2003. 125. 475

8. Merzies. D.: Dai. Q.: Bourgeois. L.: Caruso. R.: Cheng. Y.-B.: Simon. G.: Spiceia. L. Aanotechology 2007, 18. 125608.

9. Palomares, E.: Clifford. J. N.; Haque. S. A.; Lutz, T.: Durrant. J. R. Chem. Common. 2002, 1464.

10. Zabant. A.: Chen. S. G.: Chappel. S.: Gregg. B. A. Chent Conmum. 2000. 2231

11. Barbé. C. T.: Arendse F.: Comte P.: Jirousek. M.: Lenzmann1. F.: Shklover. V.: Grătzel, M. J. Am. Ceram. Soc. 1997,80. 3157.

12. Ito. S.: Liskia, P.: Comte. P.: Charvet. R.: Pechy, P.: Bach. U.: Schmidt-Mende, L.: Zakeeruddin. S. M.; Kay. A.; Nazeeruddin. M. K.: Grätzel. M. Chent. Conmum. 2005. 4351

13. Sommeling. P. M.: O'Regan. B. C.: Haswell. R. R.: Snit. H. J. P.: Bakker. N. T.: Smits. T. T. T.: Kroon. I. M.: Roosmalen. T. A. M. van J. Phus. Chem. B 2006. 110. 19191.

14. Nazeeruddin, M. K; Kay, A.: Rodicio. I.: Humphry-Baker, R. Müller. E.; Liska. P.; Vlachopoulos, N.: Grătzel, M. $j$. Am Chem. Soc. 1993. 115.6382

15. Lee. U.-H.: Kim. M.-H.: Kwon. Y.U. Bull. Korean Chen. Soc 2006. 27. 808 .

16. Koh. C.-W; Lee, U.-H; Song. J.-K.: Lee, H.-R.: Kim, M.-H.: Suh. M.: Kwon, Y.-U. Chem -Asian J. in press.

17. Kambe. S.: Nakade, S. Wada, Y: Kitamura, T.: Yanagida, S. d. Mater Chem. 2002. 12.723,

18. Chappel. S.: Chen. S.-G.: Zaban. A. Lamgntuir 2002. 18. 3336

19. Huang. S. Y.: Schichthörl. G: Nozik. A. T.: Grätzel. M.: Frank. A. J. J. Phis. Chem B 1997, 101. 2576. 